\title{
Animasi Interaktif Pengenalan Negara ASEAN Menggunakan Metode Multimedia Development Life Cycle
}

\author{
Panggi Anwar Saputra ${ }^{1}$, Endang Retnoningsih 1," \\ * Korespondensi: e-mail: endang.retnoningsih@binainsani.ac.id
}

\begin{abstract}
1 Program Studi SIstem Informasi; Universitas Bina Insani; Jl.Siliwangi No.6 Rawa Panjang Bekasi Timur 17144 Indonesia, telp (021) $82436886 /$ (021) 82436 996. Fax. (021) 824009 24; e-mail: panggi.digital@gmail.com,
\end{abstract} endang.retnoningsih@binainsani.ac.id

Submitted: 10 Oktober 2020

Revised: 31 Oktober 2020

Accepted: 14 November 2020

Published: $\mathbf{3 0}$ November 2020

\begin{abstract}
The use of technology automatically makes it easy to convey information. In this research, the use of technology can be done by using interactive animation to convey knowledge about ASEAN countries. The problem is that conventional methods are still used, namely only using books as a way of delivering learning material. Therefore, a learning medium is made using interactive animation, as a support in the delivery of learning material so that students are more enthusiastic about learning. The purpose of making this learning media is to help students get to know more deeply about ASEAN countries developed with Adobe Flash Professional CC 2015. This research uses the Multimedia Development Life Cycle (MDLC) method with six stages, namely: Concept, Design. (Design), Material Collecting, Assembly, Testing, and Distribution. The result of this research is an application to introduce ASEAN countries which is equipped with materials, games, videos and quizzes to train students' abilities.
\end{abstract}

Keywords: ASEAN, Interactive Animation, History, $M D L C$

Abstrak

Pemanfaatan teknologi secara otomatis memberi kemudahan dalam penyampaian sebuah informasi. Dalam penelitian ini pemanfaatan teknologi dapat dilakukan dengan menggunakan animasi interaktif untuk menyampaikan pengetahuan tentang negara-negara ASEAN. Permasalahan yang ada adalah masih digunakan metode konvensional yaitu hanya menggunakan buku sebagai salah satu cara penyampaian materi pembelajaran. Oleh karena itu, di buatlah suatu media pembelajaran dengan mengunakan animasi interaktif, sebagai pendukung dalam penyampaian materi pembelajaran agar siswa lebih semangat untuk belajar. Tujuan dari pembuatan media pembelajaran ini adalah untuk membantu siswa lebih mengenal secara dalam mengenai negara-negara ASEAN yang dikembangkan dengan Adobe Flash Profesional CC 2015. Penelitian ini mengunakan metode Multimedia Development Life Cycle (MDLC) dengan enam tahapan yaitu: Konsep (Concept), Perancangan (Design), Pengumpulan Bahan (Material Collecting), Pembuatan (Assembly), Pengujian (Testing), dan Distribusi (Distribution). Hasil dari penelitian ini adalah sebuah aplikasi pengenalan negara-negara ASEAN yang dilengkapi dengan materi, permainan, video dan kuis untuk melatih kemampuan siswa.

Kata kunci: ASEAN, Animasi Interaktif, Sejarah, Multimedia Develompment Life Cycle 


\section{Pendahuluan}

Penyampaian materi dalam pembelajaran menggunakan metode konvensional biasanya dilakukan dengan cara guru menyampaikan materi kepada muridnya di depan kelas dengan menggunakan media papan tulis dalam menyampaikan materi dan penjelasan secara lisan, hal ini yang menyebabkan siswa kurang paham dalam penyampaian materi karena kurangnya visualisasi dari materi yang disampaikan. Pada pelajaran mengenai pengenalan negara-negara ASEAN khususnya kelas 6 Sekolah Dasar, materi pelajaran berupa teks dan gambar dapat membuat siswa merasa pemahaman terhadap materi pelajaran kurang. Selain itu, belum adanya media pembelajaran berbasis multimedia mengenai materi negara-negara ASEAN yang bisa digunakan sebagai media penyampaian materi secara maksimal, mudah dipahami dan lebih interaktif. Penyampaian pembelajaran yang bersifat klasikal dapat menyebabkan siswa bosan (Hardayani \& Herlawati, 2016).

Penggunaan animasi interaktif merupakan solusi yang terbaik untuk memecahkan permasalahan yang ada, selain dapat digunakan sebagai media pembelajaran, animasi interaktif juga dapat menghilangkan rasa bosan terhadap aktivitas anak sehari-hari (Ariyati \& Misriati, 2016). Dalam pembuatan animasi agar menarik, haruslah memenuhi prinsip-prinsip animasi, seperti adanya efek peningkatan kecepatan terjadi distorsi bentuk, pengadegan dengan menempatkan satu objek atau lebih dalam satu frame yang disebut staging, dan aspek paling krusial pada penggarapan animasi adalah unsur timing (Soenyoto, 2017).

Penggunaan media pembelajaran sebagai hal penting untuk memotivasi siswa, keunggulannya lebih interaktif, animasi yang menarik karena audiovisual sehingga tidak bosan (Murawan, 2015). Sebuah perangkat multimedia interaktif yang mampu menggabungkan teks, gambar, audio dan animasi dalam satu kesatuan didalam smartphone android, dapat mendukung proses belajar menjadi dinamis dan interaktif untuk pembelajaran yang sifatnya individual, dapat menarik minat belajar siswa dengan menggunakan multimedia interaktif (Indarti, 2017). Aplikasi animasi interaktif yang menyediakan fasilitas bagi para siswa dan guru dalam proses belajar mengajar menjadi lebih menarik dan menyenangkan (Hidayatun, Rosmiati, \& Purnama, 2018). Suatu media yang dihadirkan dengan memanfaatkan teknologi komputer berbentuk multimedia interaktif, perangkat lunak dan keras yang mendukung dalam penerapannya adalah Adobe Flash Profesional CS6 (Fitria \& Septiana, 2016). Media sebagai alat memindahkan informasi atau pesan dari sumber melaui perangkat kepada penerima pesan (Wibawanto, 2017).

Pengenalan profil negara ASEAN menggunakan media pembelajaran buku sebagai media pemelajaran dirasa kurang memberikan informasi secara maksimal, oleh karenanya perlu dirancang aplikasi menggunakan library Vuforia dengan menggunakan marker sebagai tempat tampilnya objek 3 dimensi. Aplikasi pengenalan profil negara di ASEAN dibuat melalui beberapa tahapan yaitu pembuatan objek 3 dimensi, pembuatan marker dan pengembangan aplikasi. Objek bangunan masing-masing negara di ASEAN terdapat 10 ikon dari 10 negara. Hasil kerja aplikasi augmented reality ASEAN yaitu dalam media cetak berupa buku yang 
berisikan marker yang dapat menampilkan objek 3 dimensi serta narasi berupa suara penjelasan ikon negara di negara ASEAN (Astridefi, Sasmita, \& Rusjayanthi, 2016).

\section{Metode Penelitian}

Dalam penelitian ini metode yang digunakan adalah Multimedia Development Life Cycle, dimana metode ini memiliki enam tahapan, yaitu concept, design, material collecting, assembly, testing dan distribution, seperti gambar 1 (Munir, 2012).

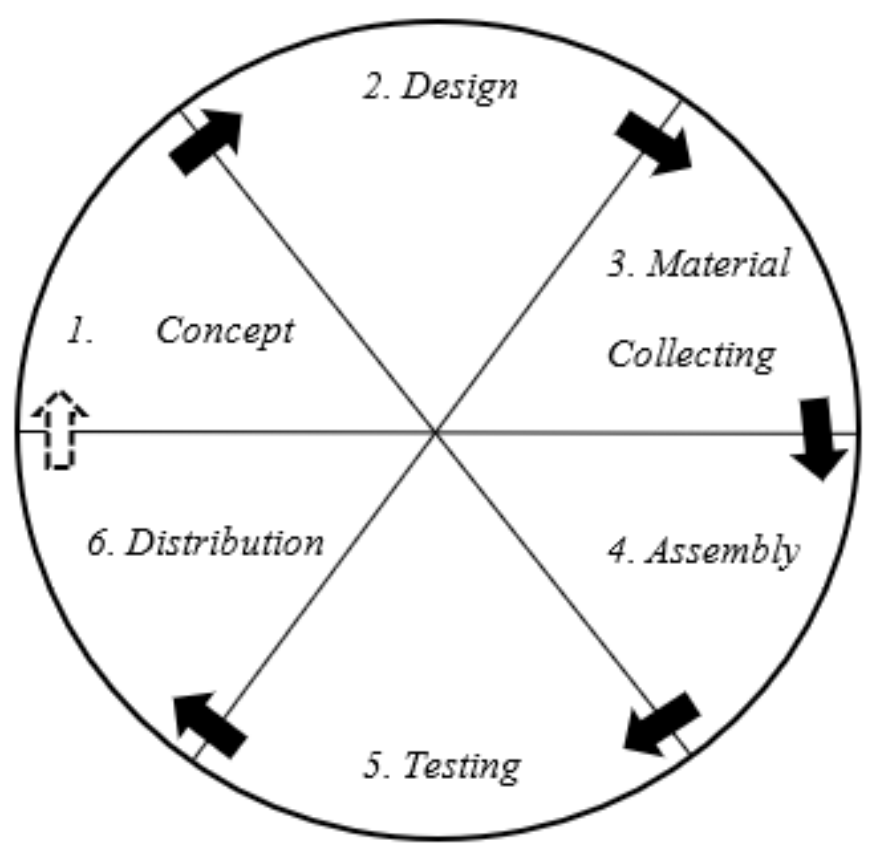

Sumber: (Munir, 2012).

Gambar 1. Metodologi Pengembangan Multimedia

Teknik pengumpulan data dilakukan dengan kegiatan observasi ke SDN Harapan Baru II Bekasi yang beralamat di Jalan perjuangan No.29 Kelurahan Harapan Baru Kecamatan Bekasi Utara yang berada di wilayah pemerintahan kota Bekasi Provinsi Jawa Barat. Kegiatan yang di lakukan adalah mengamati proses pembelajaran mengenai materi pengenalan negaranegara ASEAN pada kelas 6, mengamati suasana kelas saat guru memberikan materi, dan mencatat masalah yang dihadapi saat proses belajar mengajar. Selain observasi juga dilakukan kegiatan wawancara kepada Guru pengajar mata pelajaran IImu Pengetahuan Sosial (IPS) untuk Kelas 6 . Studi pustaka dilakukan untuk mempelajari dan mengumpulkan informasi melalui buku-buku, jurnal, internet dan sumber-sumber lainnya. Kerangka pemikiran menggambarkan langkah-langkah yang akan dilakukan dalam penyelesaian masalah, adapun kerangka kerja penelitian yang digunakan seperti terlihat pada Gambar 2.

Pertama tahap konsep (concept) adalah tahap untuk menentukan tujuan dan siapa pengguna program (identifikasi audience). Selain itu menentukan macam aplikasi (presentasi, interaktif, dan lain-lain). Kedua perancangan (design) tahap membuat spesifikasi mengenai 
arsitektur program, gaya, tampilan dan kebutuhan material/bahan untuk program. Ketiga pengumpulan bahan materi (material collecting) tahap dimana pengumpulan bahan yang sesuai dengan kebutuhan dilakukan, tahap ini dapat dikerjakan paralel dengan tahap assembly. Pada beberapa kasus, tahap Material Collecting dan tahap Assembly akan dikerjakan secara linear dan paralel. Kelima pembuatan (assembly) tahap dimana semua objek atau bahan multimedia dibuat. Pembuatan aplikasi didasarkan pada tahap design. Keenam pengujian (testing), dilakukan setelah selesai tahap pembuatan (assembly) dengan menjalankan aplikasi/program dan dilihat apakah ada kesalahan atau tidak. Tahap ini disebut juga sebagai tahap pengujian alpha (alpha test) dimana pengujian dilakukan oleh pembuat atau lingkungan pembuatnya sendiri (Munir, 2012).

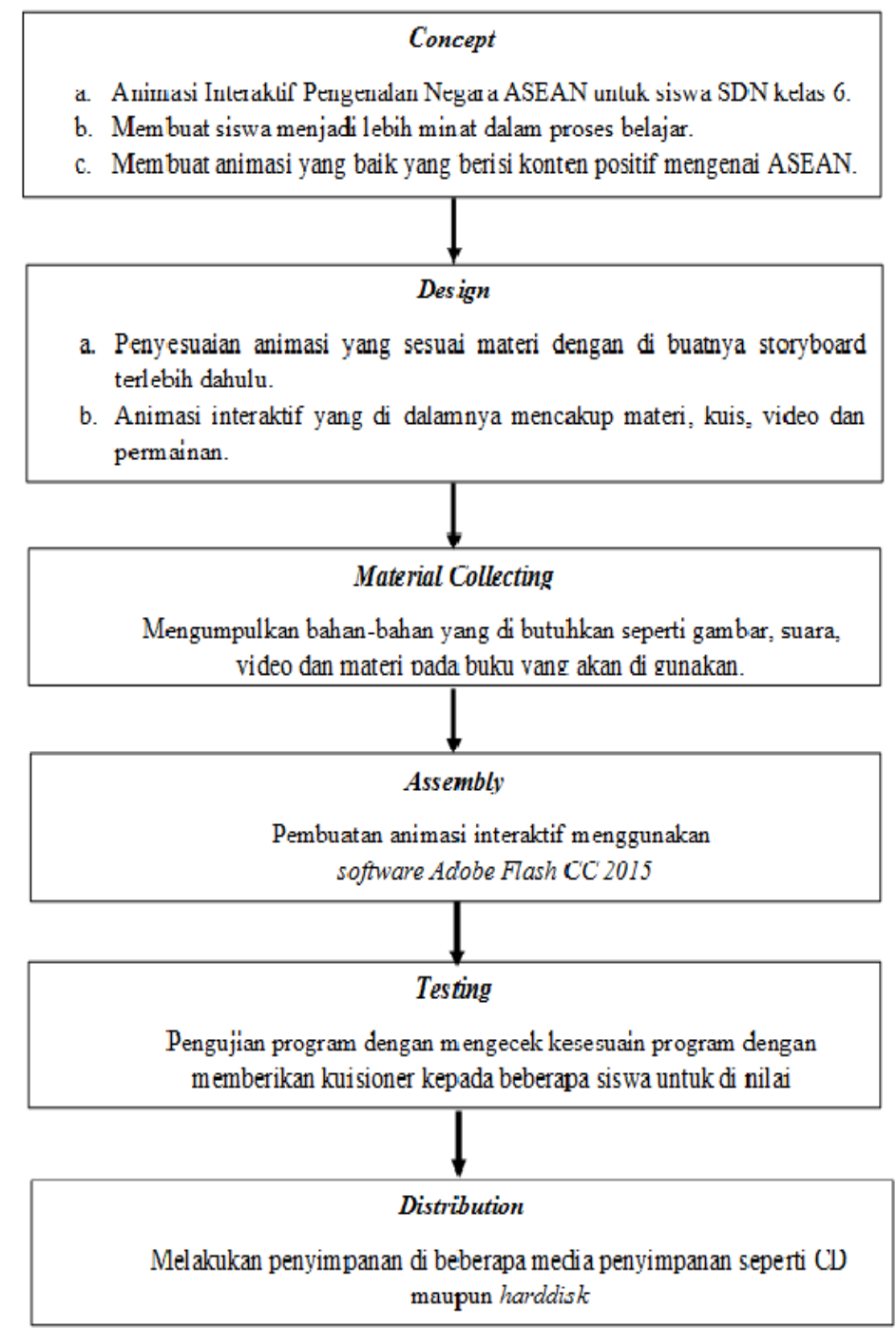




\section{Hasil dan Pembahasan}

Sesuai dengan tahapan pada metode Multimedia Development Life Cycle (MDLC) dengan enam tahapan yaitu: Konsep (Concept), Perancangan (Design), Pengumpulan Bahan (Material Collecting), Pembuatan (Assembly), Pengujian (Testing), dan Distribusi (Distribution), berikut tahapan penelitian dalam pembuatan animasi interaktif pengenalan negara ASEAN.

\subsection{Konsep (Concept)}

Dalam proses ini menjelaskan tentang pelaksanaan pembelajaran ilmu pengetahuan sosial (IPS) tentang pengenalan negara-negara ASEAN. Dalam bentuk evaluasi belajar siswa, siswa diharuskan mengingat pelajaran yang ada dibuku dalam bentuk teks, jika siswa tidak memiliki minat membaca yang kuat maka dalam proses pembelajaran tidak akan memuaskan. Pada proses ini, guru menyampaikan materi sesuai kompetensi dasar dan indikator yang telah ditetapkan pada silabus pembelajaran. Buku materi digunakan sebagai media penyampaiannya. Soal diberikan ketika materi sampai pada akhir penyampaian (akhir bab). Guru dapat menyampaikan kembali materi yang belum dipahami siswa sebagai bentuk evaluasi. Hal ini dapat diukur dan dilihat dari persentase nilai akhir yang di dapat oleh siswa pada soal yang telah diberikan.

\subsection{Perancangan (Design)}

Pada tahap ini membuat dapat dimulai dengan membuat use case diagram dan storyboard. Gambar 3 adalah Use Case Diagram animasi interaktif pengenalan negara-negara ASEAN:

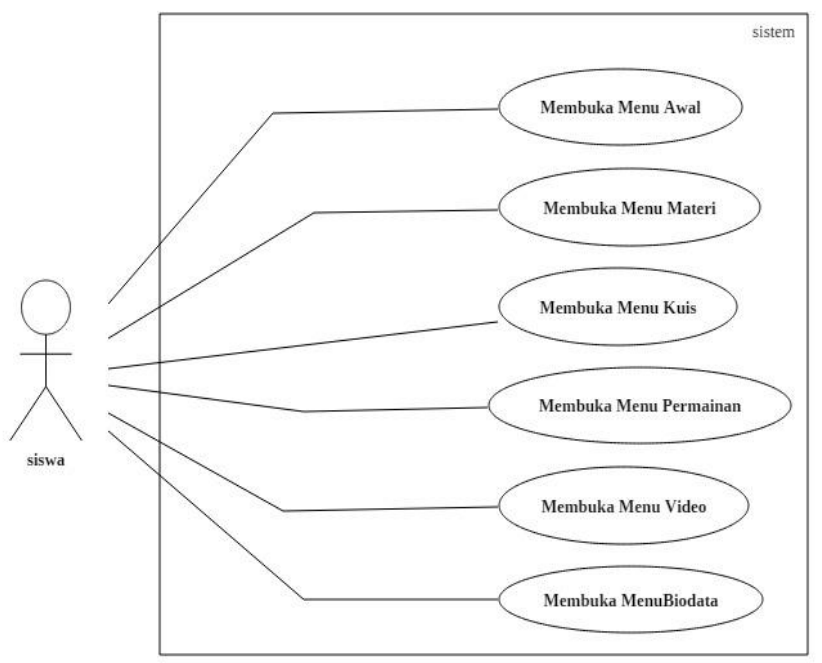

Sumber: Hasil Penelitian (2019)

Gambar 3. Use Case Diagram Animasi Interaktif

Perancangan menggunakan use case diagram akan memberi gambaran bagaimana fungsi-fungsi yang ada di dalam sistem akan berinteraksi dengan pengguna, sedangkan perancangan storyboard menjelaskan bagaimana aplikasi berjalan. Use case diagram menggambarkan cara user berkomunikasi dengan sistem yang berjalan dan berfungsi untuk mengetahui fungsi-fungsi yang ada didalam sistem, 
Scenario use case dibuat sesuai dengan use case diagram yang dibuat pada animasi interaktif terdiri dari membuaka menu awal, membuka menu materi, membuka menu kuis, membuka menu permainan, membuaka menu video, dan membuaka menu biodata. Menu Awal menggambarkan proses dimana pengguna baru membuka dan menjalankan aplikasi, yang mengarah langsung untuk masuk ke menu utama. Menu awal sendiri adalah halaman pertama yang tampil sebelum user/pengguna memulai dan masuk ke menu utama aplikasi dimana terdapat menu-menu yang akan dipilih oleh pengguna. Tabel 1 menunjukkan scenario use case halaman utama.

Tabel 1. Scenario use case Menu Utama

\begin{tabular}{|c|c|}
\hline Nama Use Case & Menu Awal \\
\hline Aktor & Siswa \\
\hline Deskripsi & Proses dimulai ketika siswa membuka aplikasi \\
\hline \multirow[t]{2}{*}{ Pre-condition } & Aktor telah menjalankan program \\
\hline & Sistem \\
\hline \multirow[t]{5}{*}{ Skenario Normal } & 1. Membuka Apikasi \\
\hline & 2. $\quad$ Menampikan Menu Awal \\
\hline & 3. Mengklik button \\
\hline & Masuk \\
\hline & 4. Masuk Menu Utama \\
\hline Post-condition & Aktor kembali membuka aplikasi \\
\hline
\end{tabular}

Berikut storyboard pada pembuatan animasi pengenalan negara ASEAN mulai dari menu awal, menu utama, materi, kuis, video, permainan dan biodata.

Tabel 2. Storyboard Animasi Interaktif Pengenalan Negara-Negara ASEAN

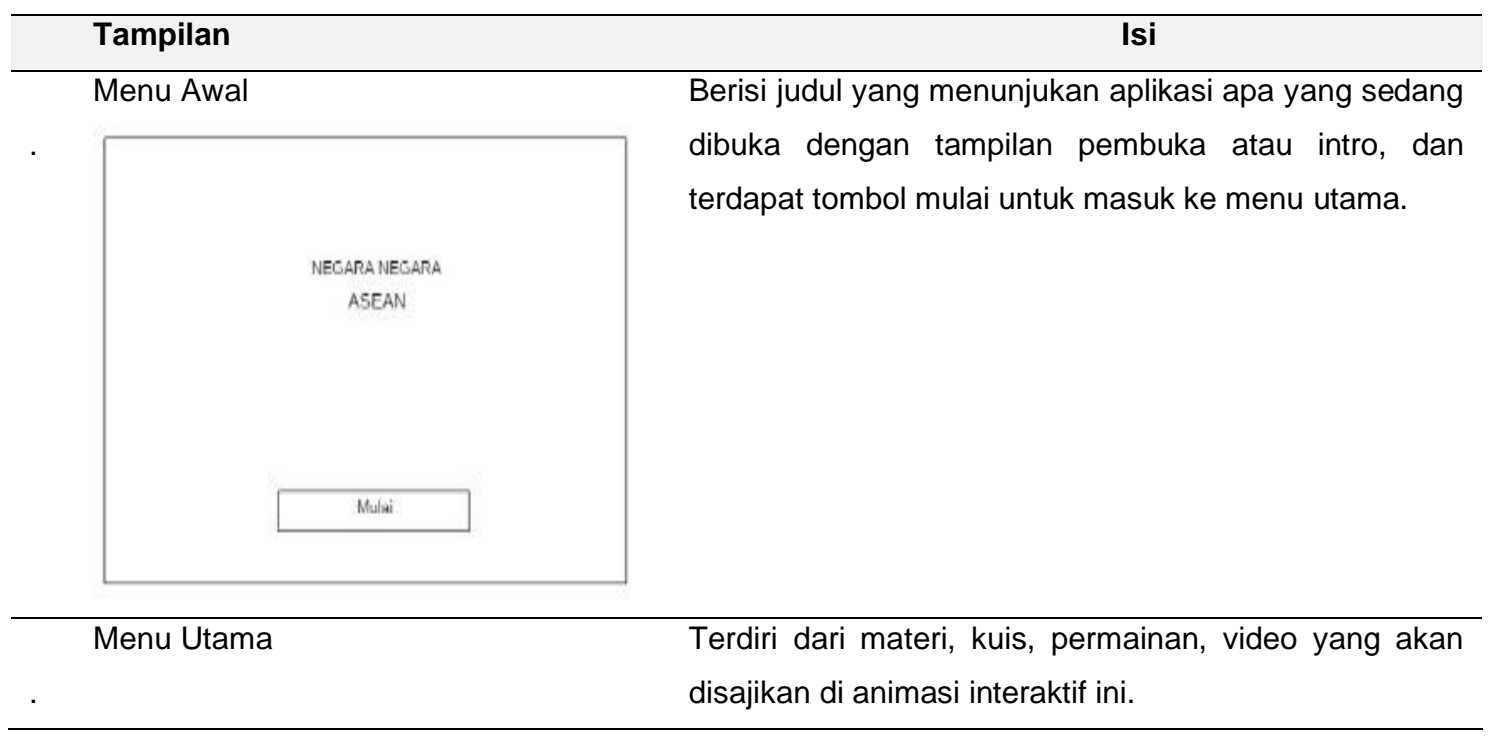




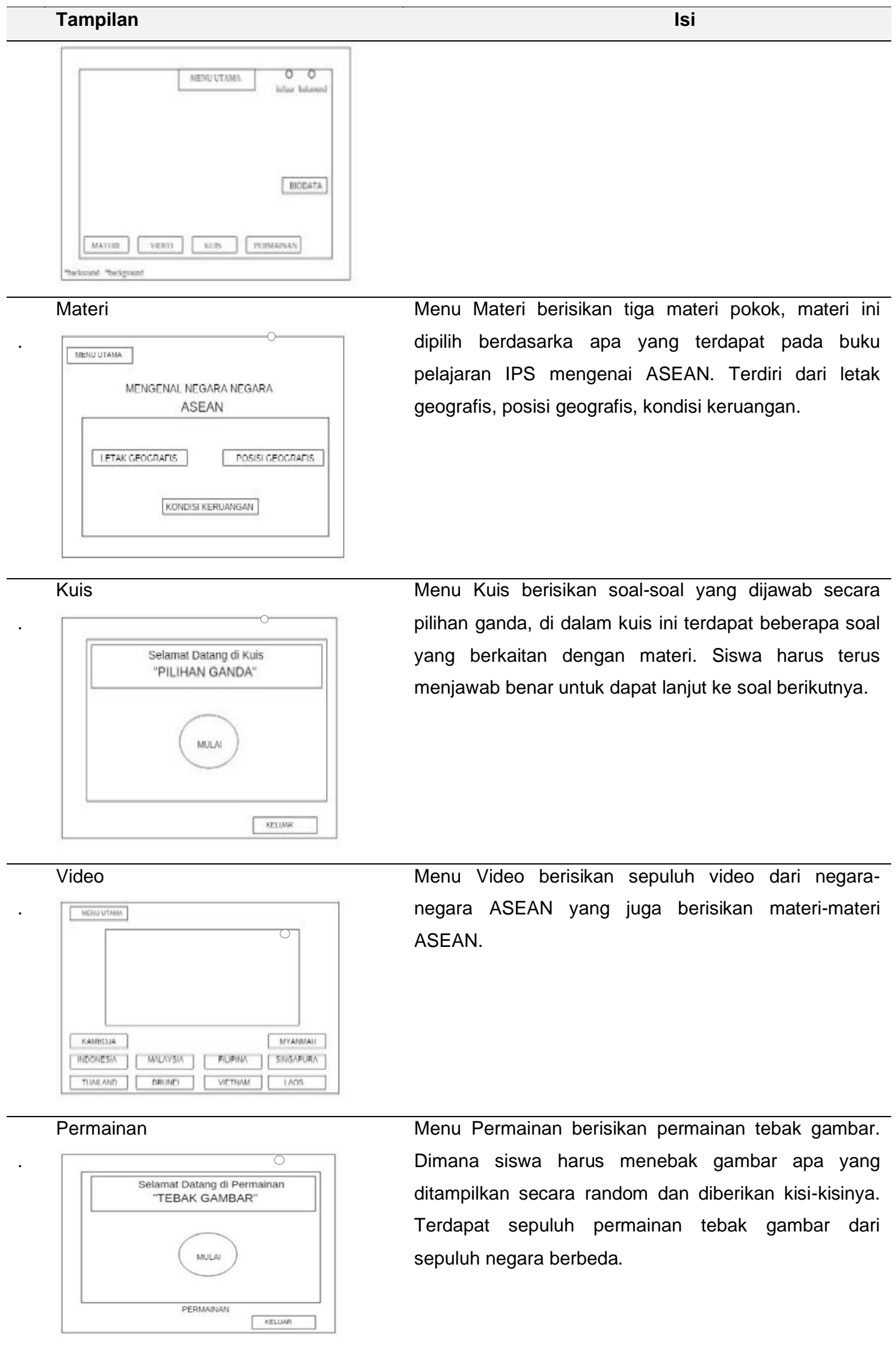

Sumber: Hasil Penelitian (2019) 


\subsection{Pengumpulan Bahan (Material Collecting)}

Tahap pengumpulan bahan yang sesuai dengan kebutuhan seperti sumber untuk menyusun materi dalam animasi interaktif pengenalan negara ASEAN harus sesuai dengan kurikulum yang digunakan di Sekolah Dasar untuk kelas 6 yang berlaku secara nasional. Materi pembelajaran yang diberikan guru dalam bentuk kompetensi dasar dan indikator pembelajaran dalam periode satu tahun, pada penelitian ini digunakan kurikulum 2013 yaitu buku yang digunakan untuk membuat material animasi yang didalamnya terdapat penjelasan terkait negara-negara ASEAN yang akan di bahas dalam aplikasi yaitu Brunai, Kamboja, Indonesia, Vietnam, Laos, Malaysia, Myanmar, Filipina, Thailand, Singapura.

\subsection{Pembuatan (Assembly)}

Pada tahap dibuat animasi interaktif pengenalan negara-negara ASEAN, aplikasi dijalankan dalam format .swf dengan bahasa pemrograman ActionScript 3.0. Gambar dan audio di unduh dan disempurnakan dengan software pendukung yang digunakan. Tabel 3 hasil pembuatan yang dilakukan.

Table 3. Hasil Pembuatan Animasi Interaktif
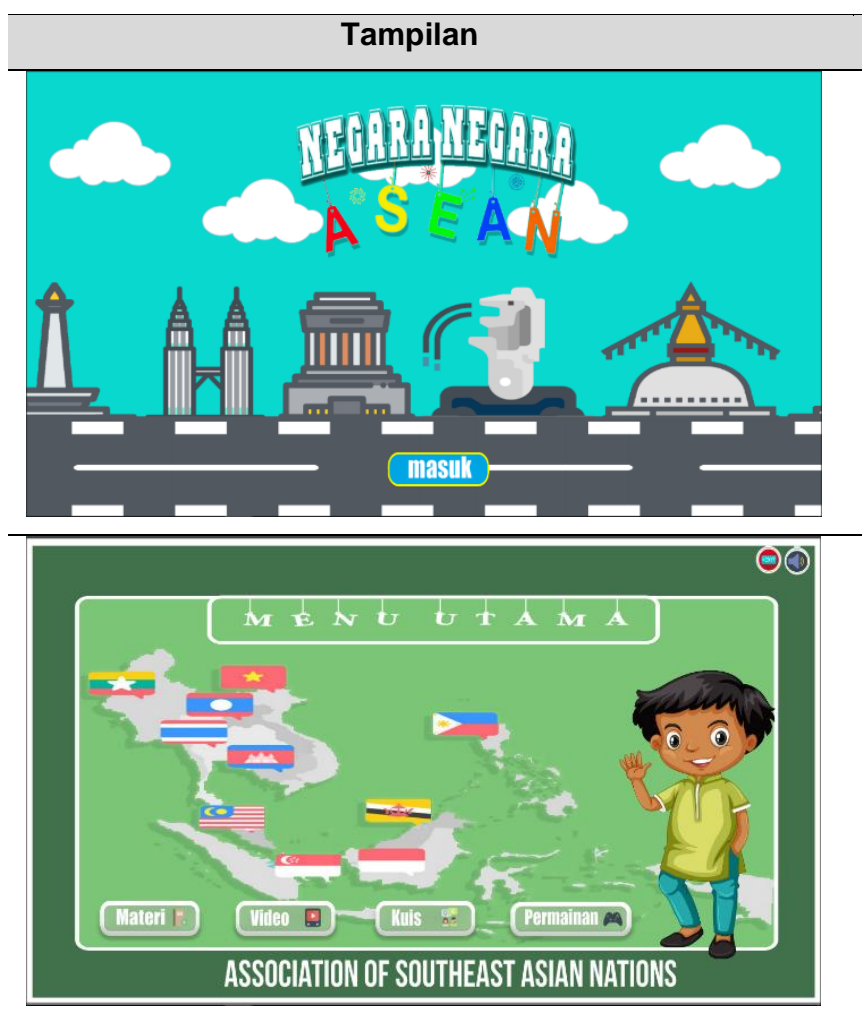

1. Tampilan Halaman Awal.

Halaman yang pertama kali muncul ketika kita membuka aplikasi, halaman ini berisi judul dan gambaran awal mengenai aplikasi animasi interaksi.

\section{Tampilan Menu Utama.}

Halaman menu utama adalah halaman utama yang di dalamnya terdapat $4 \mathrm{sub}$ menu. Kita bisa memilih tiap menu dengan mengklik tombol pada masingmasing menu.

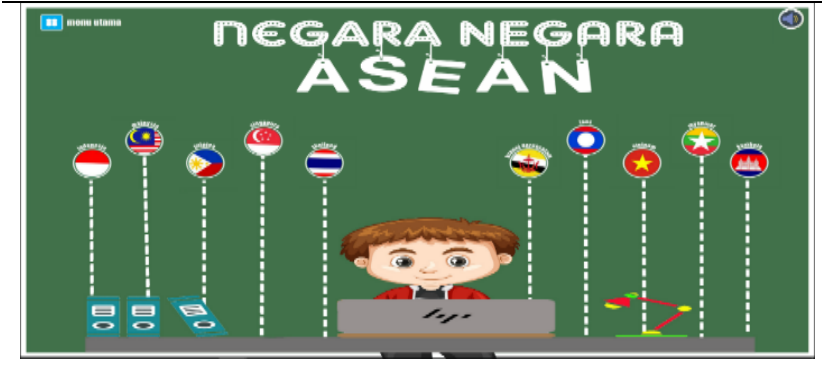

3. Tampilan Halaman Materi Kondisi Keruangan.

Halaman ini diisi oleh materi-materi mengenai kondisi keruangan yang ada di negara ASEAN. Mayoritas materi diambil dari buku materi pelajaran IPS kelas 6 . Isi dari halaman materi kondisi keruangan 


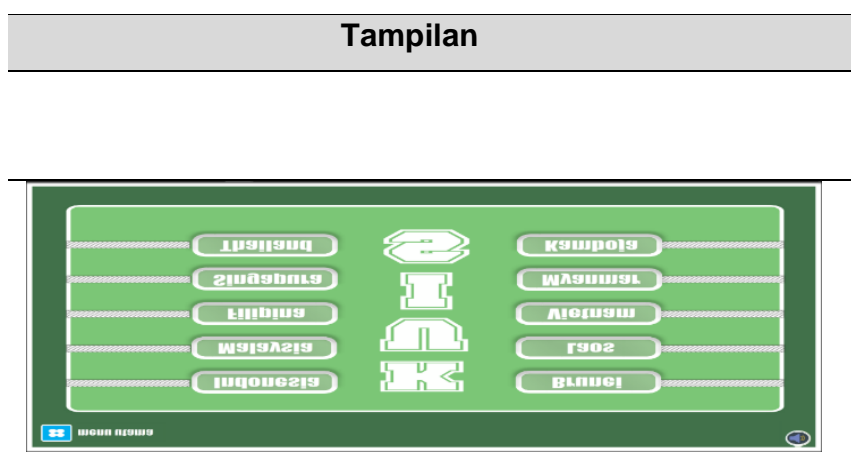

Penjelasan
terdiri dari beberapa halaman sebagai

berikut.

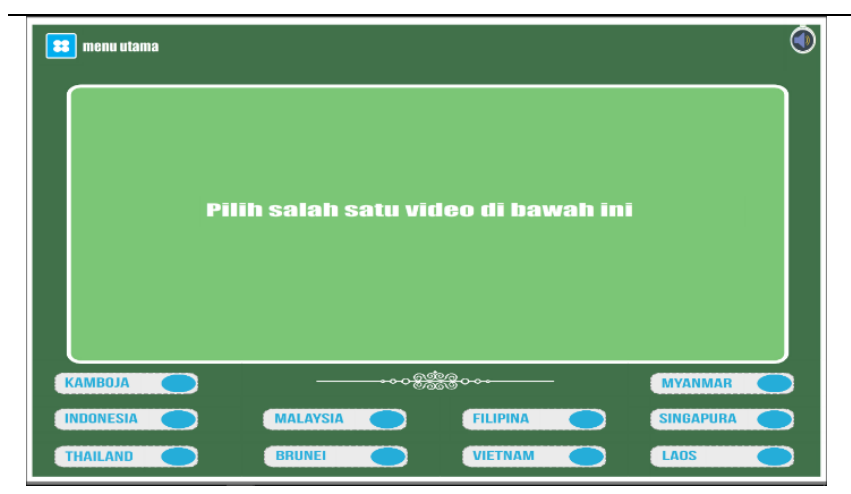

4. Halaman Menu Kuis

Halaman ini merupakan halaman awal Kuis sebelum masuk ke isi kuis yang sebenarnya.

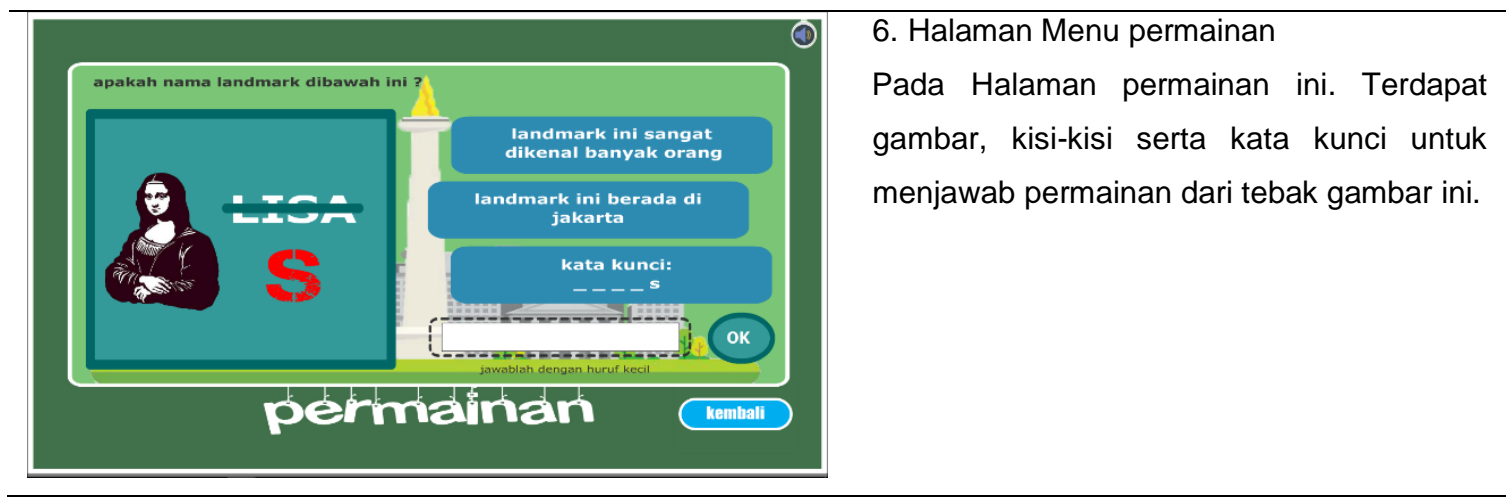

Sumber: Hasil Penelitian (2019)

\subsection{Pengujian (Testing)}

Pengujian Pogram merupakan hal terpenting yang bertujuan untuk menemukan kesalahan-kesalahan atau kekurangan-kekurangan pada perangkat lunak yang akan diuji, dengan menggunakan metode blackbox dan whitebox sistem akan menjadi lebih baik dan temuan kesalahan dapat diminimalisir. Berikut adalah proses pengujian program yang telah dilakukan.

\section{Pengujian Blackbox}

Dilakukan pada dua perangkat berbeda, yaitu PC dan Laptop. Pengujian dilakukan pada setiap menu yang terdapat dalam aplikasi, contoh pada tabel 4 pengujian menu awal dilakukan untuk melihat kesesuaian fungsi pada program awal. Halaman ini adalah halaman awal yang muncul saat menjalankan program. Tabel 4 pengujian blackbox dari menu awal pada aplikasi animasi interaktif pengenalan negara-negara ASEAN. 
Tabel 4. Pengujian Blackbox Menu Awal

\begin{tabular}{|c|c|c|c|}
\hline Skenario Pengujian & Test Case & Hasil yang diharapkan & Hasil \\
\hline Menjalankan Program & $\begin{array}{l}\text { Pengguna membuka } \\
\text { aplikasi }\end{array}$ & Tampil Halaman awal & Sesuai \\
\hline Masuk menu utama & $\begin{array}{l}\text { Pengguna menekan tombol } \\
\text { Masuk }\end{array}$ & $\begin{array}{l}\text { Tampil Halaman menu } \\
\text { utama }\end{array}$ & Sesuai \\
\hline
\end{tabular}

Sumber: Hasil Penelitian (2019)

\section{Pengujian WhiteBox}

Secara sekilas dapat diambil kesimpulan whitebox testing merupakan petunjuk untuk mendapatkan program yang benar. Pengujian whitebox berfokus pada struktur kontrol program sebagaimana pada gambar 4 .

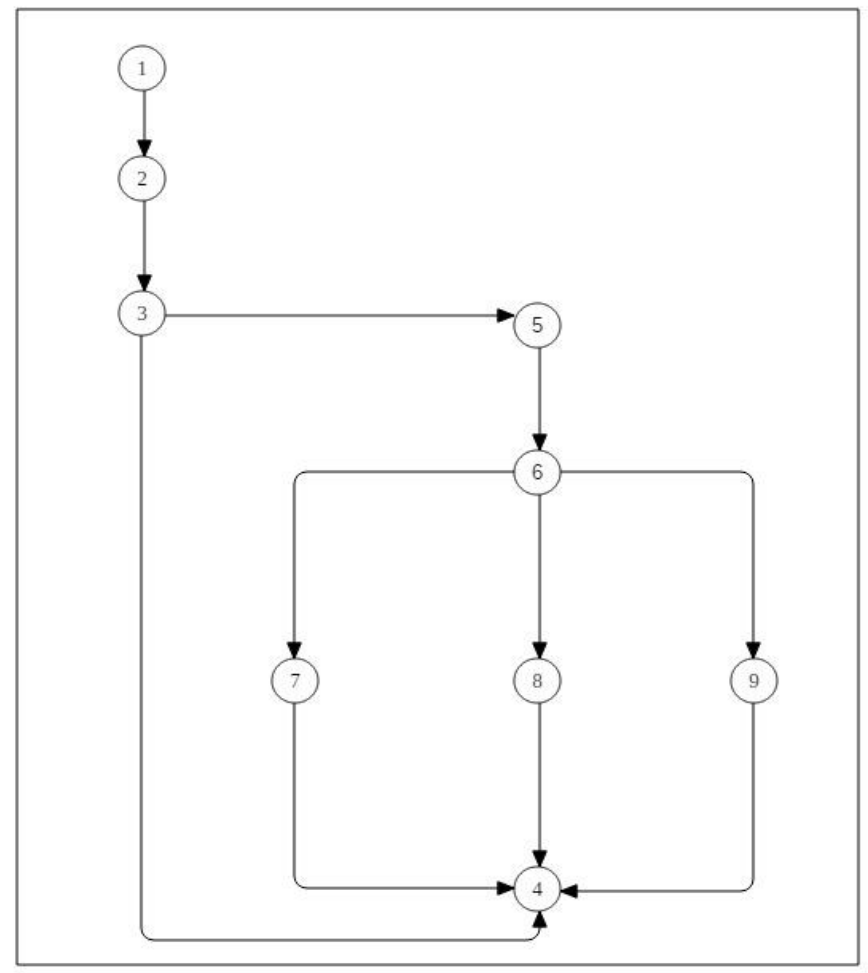

Sumber: Hasil Penelitian (2019)

Gambar 4. Grafik Alir Menu Materi

Kompleksitas Siklomatis (pengukuran kuantitatif terhadap kompleksitas logis suatu program) dari grafik alir dapat diperoleh dengan perhitungan:

$$
\mathbf{V}(\mathbf{G})=\mathbf{E}-\mathbf{N}+\mathbf{2}
$$

$\mathrm{E}$ = Jumlah edge grafik alir yang ditandakan dengan gambar panah

$\mathrm{N}$ = Jumlah simpul grafik alir yang ditandakan dengan gambar lingkaran

Sehingga kompleksitas siklomatisnya

$V(G)=11-9+2=4$ 
Basis set yang dihasilkan dari jalur independent secara linier adalah jalur sebagai berikut:

1) $1-2-3-4$;

2) $1-2-3-5-6-7-4$;

3) $1-2-3-5-6-8-4$;

4) 1-2-3-5-6-9-4;

Ketika aplikasi dijalankan, maka terlihat bahwa salah satu basis set yang dihasilkan adalah 1-2-3-4-5, dan terlihat bahwa simpul telah dieksekusi satu kali. Dengan ketentuan tersebut dari kelayakan software, sistem menu ini telah memenuhi syarat.

\subsection{Distribusi (Distribution)}

Tahap dimana aplikasi disimpan dalam suatu media penyimpanan, seperti hardisk dan $C D$ yang sebelumnya sudah dijadikan file autoplay. Tahap merupakan tahap akhir dimana media (dalam bentuk $C D$ ) telah siap untuk dioperasikan maupun digandakan untuk dipublikasikan. File-file disimpan dalam bentuk *.fla (flash CS6 document). Setelah aplikasi selesai dibuat, aplikasi di-export menjadi file *.exe, agar aplikasi tersebut dapat dijalankan dengan mudah di perangkat komputer.

\section{Kesimpulan}

Setelah melakukan penelitian mengenai proses pembelajaran dan mengajar yang selama ini dilakukan secara konvensional menjadi berbasis komputer dengan menggunakan media pembelajaran animasi interaktif. Dengan adanya animasi interaktif ini memudahkan siswa dalam memahami mata pelajaran ilmu pengetahuan sosial. Menjadi lebih semangat, terfokus dan terpacu untuk melihat isi tampilan pada animasi interaktif ini. dengan animasi yang bersifat user friendly memudahkannya secara cepat pada anak. Dengan diterapkannya animasi interaktif dalam proses belajar mengajar, dapat memotivasi para pengajar agar selalu kreatif dan mencapai tujuan pembelajaran dengan hasil yang maksimal. Dalam perancangan animasi interaktif ini dengan menggunakan visualisasi gambar, suara, grafik dengan tampilan yang tidak monoton, dan memasukan video akan membuat animasi interaktif yang disampaikan lebih mudah untuk meningkatkan daya ingat atau daya tangkap pada siswa. Saran untuk penelitian selanjutnya di harapkan adanya pembuatan aplikasi animasi interaktif dengan mata pelajaran lain, diharapkan adanya pembuatan permainan yang lebih banyak lagi dan mengarah pada materi pembelajaran, materi harus lebih banyak menggunakan gambar-gambar yang lebih menarik.

\section{Daftar Pustaka}

Ariyati, S., \& Misriati, T. (2016). Perancangan Animasi Interaktif Pembelajaran Asmaul Husna. Jurnal Teknik Komputer AMIK BSI, 2(1), 116-121.

Astridefi, A., Sasmita, G. M. A., \& Rusjayanthi, N. K. D. (2016). Aplikasi Pengenalan Profil Negara di ASEAN Berbasis Augmented Reality. Merpati, 4(1), 162-169. 
Fitria, D., \& Septiana, A. (2016). Perancangan Animasi Interaktif Pengenalan Tata Surya Untuk Siswa Sekolah Berbasis Android. In SNIPTEK (Seminar Nasional Ilmu Pengetahuan dan Teknologi Komputer Nusa Mandiri) (pp. 303-308). Jakarta. Retrieved from https://konferensi.nusamandiri.ac.id/proceeding/index.php/sniptek/article/view/113/113.

Hardayani, S. E., \& Herlawati. (2016). Animasi Interaktif Pengenalan Hewan Khas Pulau Indonesia Berbasis Android Pada TK Kupu-Kupu Mungil Bekasi. Jurnal Teknik Komputer AMIK BSI, 2(1), 9-21.

Hidayatun, N., Rosmiati, M., \& Purnama, M. R. (2018). Animasi Interaktif Berbasis Android Untuk Mengenal Huruf Hiragana Katakana. Journal Speed - Sentra Penelitian Engineering Dan Edukasi, 10(1), 1-8.

Indarti. (2017). Aplikasi Pengenalan Pahlawan NAsional di Pulai Jawa untuk Siswa SD Berbasis Android Studi Kasus pada SDN Pondo Pinang 10 Pagi Jakarta Selatan. Jurnal Pilar Nusa Mandiri, 13(1), 145-150. Retrieved from http://ejournal.nusamandiri.ac.id/ejurnal/index.php/pilar/article/view/349/281

Munir. (2012). Multimedia Konsep dan Aplikasi dalam Pendidikan. Bandung: Alfabeta.

Murawan. (2015). Perancangan Media Pembelajar Interaktif Berbasis Adobeflash Profesional CS6 Untuk Meningkatkan Motivasi Belajar Siswa SMA. Seminar Nasional Pendidikan Sains UKSW.

Soenyoto, P. (2017). Animasi 2D. Jakarta: Elex Multi Media.

Wibawanto, W. (2017). Desain dan Pemrograman Multimedia Pembelajaran Interaktif. Jember:

Cerdas Ulet Kreatif. 